\title{
Beyond Platform-Centrism and Digital Universalism: The Relational Affordances of Mobile Social Media Publics
}

Wendy Willems

Department of Media and Communications, London School of Economics and Political Science Department of Media Studies, University of the Witwatersrand http://orcid.org/0000-0002-9185-4268

\begin{abstract}
:
In debates on digital affordances, mobile devices and social media platforms are often treated as separate (physical or digital) objects which function independently from each other and from the environments in which they are used ('platform-centrism'). However, mobile phone use has increasingly been dominated by social media apps while social media are frequently accessed via mobile devices, particularly in Global South contexts where users often rely on mobile-only internet access via subsidized/zero-rated social media data bundles. Furthermore, the affordances of mobile social media are shaped by the physical, mediated and political contexts in which they are used. Technological affordances are far from universal ('digital universalism') but take on different shapes across the globe. Drawing on research carried out during the September 2011 Zambian elections, this article introduces the notion of 'relational affordance' to emphasize the interplay between mobile social media, users and their varied contexts. Despite the relatively low number of mobile internet users at the time, the Facebook group of the popular, privately-owned Zambian television station, Muvi TV, quickly emerged as a fast-paced forum for the sharing of information on the elections. Three 'relational affordances' infrastructure, home-based access and temporality - help to explain the emergence of this active mobile social media public. This analysis challenges previous accounts of mobile social media publics which identified negative (constraining) affordances like the control exerted by Facebook page administrators and positive (enabling) affordances such as the 'always-on' nature of mobile social media use and their 'on-the-go' access in public spaces.
\end{abstract}

\section{Original citation:}

Willems, W. (in press). Beyond platform-centrism and digital universalism: the relational affordances of mobile social media publics. In: Information, Communication and Society.

\section{Keywords:}

social media; mobile internet; affordance; publics; Global South; Zambia

\author{
Author contact details: \\ Dr Wendy Willems \\ Room TW3.7.01G \\ Department of Media and Communications \\ London School of Economics and Political Science \\ Houghton Street \\ London WC2A 2AE \\ United Kingdom \\ P: $\quad$ +44 2078523738 \\ E: w.willems@1se.ac.uk
}


The rapid rise of smartphones in the past decade has seen the proliferation of mobile internet access globally. While in 2007 only 4 percent of the global population had access to mobile internet, this increased to 62 percent a decade later (ITU, 2018).1 Reflecting ongoing global digital divides, mobile internet access is higher in the Global North. In 2017 there were 103.6 connections for every 100 inhabitants of developed countries as compared to 53.6 in developing countries. However, users in developing countries tend to rely more strongly on smartphones to access the internet; mobile-only or mobile-centric access is very common in many parts of the Global South due to low access rates to fixed broadband and the high costs of computer equipment (Donner, 2015). In 2017, only 9.7 percent of developing country dwellers had access to fixed broadband as compared to 31.6 percent of the population of developed countries (ITU, 2018). In the same year, only 34.8 percent of households in developing countries owned a computer, as compared to 81.7 percent of households in developed countries (ITU, 2018).

Smartphones have substantially expanded the number of internet users in the Global South. Prior to the emergence of the mobile internet, internet users often relied on public access points such as libraries, telecentres and internet cafés (Mwesige, 2004; Hyde-Clarke, 2006; Burrell, 2012). The spatial shift in internet access from fixed desktop computers to mobile smartphones has taken place alongside a growing popularity of social media platforms. In the context of saturating markets in the Global North, global social media platforms have extended their reach to parts of the Global South. The development of apps suitable for mobile devices has been crucial in the global expansion strategy of social media platforms (Goggin, 2014).

As their uptake continues to grow, mobile social media platforms such as Facebook, WhatsApp and Twitter have produced publics that have increasingly been implicated in political processes such as elections (Enli and Moe, 2015), protests (Gerbaudo, 2012) and everyday forms of civic engagement (Highfield, 2016). The 2011 uprising in North Africa and the Middle East (the so-called 'Arab Spring') provoked much hope about the ability of social media to function as 'technologies of freedom' and to bring about political change, particularly in the context of the Global South (Christensen 2011). This technological utopianism has resulted in a scholarly preoccupation with the impact of social media on political processes, preventing a better understanding of the causes of their growing implication in politics. This article proposes the notion of 'relational affordances' to shed light on the conditions under which mobile social media publics emerge.

The notion of affordance has regained popularity in recent years and has frequently been invoked in relation to work on digital technology, leading some scholars to refer to it as one of the 'keywords' in the field of media and communication studies (Nagy and Neff, 2015). However, discussions on digital affordances have suffered from two major limitations. First, debates have been characterized by platform-centrism, locating the affordances of social media primarily in the platforms themselves. The way in which platforms are accessed (via mobile devices for example) and the wider infrastructural, spatial and temporal context in which social media afford their uses are often disregarded. The focus on mobile social media in this article acknowledges the importance of understanding the affordances of the growing convergence between mobile and social media. Secondly, research on affordances has suffered from digital universalism (Chan, 2014), presenting the technological affordances of social media as universally valid while primarily drawing on North American and European contexts.

Moving beyond platform-centrism and digital universalism, this article deploys the notion of 'relational affordance' to gain an understanding of the interplay between technology, users and their varied contexts. It interrogates this concept through research carried out on 
mobile social media use during the September 2011 elections in Lusaka, Zambia. Despite the relatively low number of mobile internet users at the time, the Facebook group of the popular, privately-owned Zambian television station, Muvi TV, quickly emerged as a lively forum for the sharing of information on the elections. Posts made by the page administrators or general followers provoked hundreds of comments in minutes. How can we explain the emergence of this active social media public? The aim of this article is not to carry out a systematic analysis of the role of mobile social media during elections, nor to invoke a normative argument on whether or not mobile social media contribute positively or negatively to electoral processes.

Instead, the main purpose is to gain a better understanding of the key relational affordances of mobile social media publics, and secondly, in asking what Zambia might be able to contribute to existing debates on affordances. The article argues that affordances of digital technology are not universal but shaped by the contexts in which they are used. The first section critically assesses the literature on social media and mobile phone affordances and introduces the notion of relational affordances. The second section offers background on mobile social media in Zambia and the third section details the research methodology. The final section identifies three key relational affordances of mobile social media publics in Zambia: infrastructure, home-based access and temporality, which emerge out of the interaction between technology and platforms, users and their physical, mediated and political environments.

\section{Affordances, platforms and publics}

In recent years, the notion of affordance has frequently been deployed in relation to digital technology. The concept was coined by Gibson (1979, p. 127), a social psychologist, who understood it as follows: 'the affordances of the environment are what it offers the animal, what it provides or furnishes, either for good or ill'. Technological affordances of digital media can be both negative and positive. As Norman (1988, p. 82) argued, 'affordances suggest the range of possibilities, constraints limit the number of alternatives'. In recognizing the ability of users to shape technology, the notion of 'affordance' has enabled scholars to adopt a median position between technological determinism and radical constructivism. In relation to social media publics, a key strength of the concept is that it helps to emphasize that ' $\mathrm{t}$ ] he nature of publicness online is shaped by the architecture and affordances of social media, but also by people's social contexts, identities, and practices' (Baym and boyd, 2012, p. 32).

Media and communication scholars have examined the affordances of mobile phones (Schrock, 2015; Mascheroni and Vincent, 2016), social network sites (boyd, 2010; Ellison and Vitak, 2015) and social media platforms (Nagy and Neff, 2015; Ilten, 2015; Bucher and Helmond, 2017). '[P]ortability, availability, locatability, and multimediality' have been identified as key features of mobile phones (Schrock, 2015) while those highlighting the affordances of social media platforms have emphasised their interactive, participatory or networked nature (Varnelis 2008; Zayani 2015; Rambukkana 2015); their incorporation of visual communication like photos, video clips or memes (Miller and Sinanan 2017); or their emphasis on affect and emotion as expressed through emoticons and 'likes' (Papacharissi 2015). Specifically focusing on the affordances that contribute to the formation of 'networked publics', boyd (2010: 46) identifies four key features: persistence ('online expressions are automatically recorded and archived'), replicability ('content made out of bits can be duplicated'), scalability ('the potential visibility of content in networked publics is great'), and searchability ('content in networked publics can be accessed through search'). 
Thus far, debates on the affordances of mobile phones and social media platforms have been held in relatively detached networks, e.g. mobile communication studies and platform studies. However, in the last decade, their uses have converged which has made it harder to separate analyses of affordances. Mobile phone use has increasingly been dominated by social media apps, particularly in the Global South where users often rely on subsidized/zero-rated social media data bundles. Conversely, social media are frequently (only) accessed via mobile devices, again especially so in the Global South where mobile-only or mobile-centric internet access is predominant. Hence, it is important to gain a better understanding of the affordances of mobile social media, i.e. social media which are accessed from a mobile device.

A second limitation of debates is the focus on the intrinsic features of technology or the relation between users and technology, thereby neglecting the way in which broader environments and contexts shape the use of technology. While Gibson's (1979) original notion of affordances referred to the 'affordances of the environment [my italics, author]', subsequent invocations of the term have often focused on technological objects rather than ecological environments. For example, Norman (1988, p. 9) defined the concept of affordance as 'the perceived and actual properties of the thing, primarily those fundamental properties that determine just how the things could possibly be used' [my italics, author]. For Norman, affordances primarily resided in objects. Similarly, in the field of media and communications, the notion of affordance is often applied to material objects such as mobile phones or digital objects like social media platforms.

Other scholars have acknowledged the dynamic interplay between objects and users. For Knappett (2005, p. 46), affordances are relational: '[t]he affordance of an object is neither solely an independent property of the object itself, nor is it exclusively an intentional state within the mind of the person engaging with it, but a relational property shared between object and agent'. In focusing on the interaction between object and user, the relational approach to affordances avoids a technological determinist position that places the bulk of agency in the object itself. However, Knappett's approach still fails to take seriously the context in which object and user interact and are located. Affordances are not independent from their environment but contexts shape what technology affords the user. Examining the relational affordances of mobile social media recognizes that platforms afford certain uses to users because of the particular interaction they have with their context and environment. Ultimately, this enables an analytical departure away from platform-centrism and allows a move beyond digital universalism by acknowledging the varied ways in which technology is appropriated in different contexts.

\section{Social media publics, elections and the 'Ask Muvi TV' Facebook page}

Mobile social media afford many uses - personal, private, public, political, professional, entertainment. The affordances of social media in political processes are often understood in terms of enabling resistance, such as facilitating collective action (Gerbaudo 2012) or shaping the collective identity of social movements (Khazraee and Novak 2018). Instead of examining digitally mediated protest, the focus of this article is on the role of mobile social media in information sharing and constituting 'ad hoc publics' during elections (Bruns and Burgess, 2015). Irrespective of their corporate aims, social media platforms can occasionally be used for public goals or to advance public interests (boyd, 2010; Baym and boyd, 2012; Van Dijck and Poell, 2015). Nevertheless, as Poell and van Dijck (2016, p. 232) have argued, 'moments of publicness will certainly be brief, as social media are geared toward continuously connecting users to new trends and advertisements'. Like physical space, mobile social media space is 
highly disputed, most importantly serving the interests of platform owners and mobile phone networks but occasionally also meeting the concerns of other actors such as the state, citizens or non-governmental organizations.

Like elsewhere, social media have increasingly become part of political processes on the African continent (Dwyer and Molony, 2019). The hotly contested ballot held on 20 September 2011 were the first Zambian elections in which social media began to emerge as an important space in which information was shared. The 2011 elections were crucial for several reasons. Significantly, the incumbent Movement for Multi-Party Democracy (MMD), which had been in power since 1991, lost to the opposition Patriotic Front (PF) which thrived in urban areas with its 'populist' agenda and grassroots support base. The period immediately after the ballot was tense because of delays in announcing the election results, which to many Zambians suggested that the MMD was keen to cling to power. Provisional election results began to be shared informally (and illegally) on the 'Ask Muvi TV' Facebook page, which was set up by the privately-owned television station, Muvi TV, to communicate with its audiences.2 For many urban Zambians, this station had become a popular alternative to the state-controlled public broadcaster, the Zambia National Broadcasting Corporation (ZNBC). While ZNBC largely mediated the voice of political elites, Muvi TV aspired to be the voice of ordinary Zambians (Wasserman and Mbatha, 2017). The content and news programs broadcast by the channel strongly resonated with the populist agenda of the opposition Patriotic Front (PF).

The key aim of the 'Ask Muvi TV' page was to engage with the television station's audiences. The page administrators provided followers with regular updates on programs. The page explicitly invited users to ask questions about the station which page administrators would answer publicly (through replies to comments). The page was remarkable for several reasons. First of all, with an estimated total of 117,520 Facebook users in 2011 (as compared to 1.6 million in December 2017), the number of social media users in Zambia was relatively small. 3 However, with 24,981 likes (on 13 October 2011), the 'Ask Muvi TV' page significantly brought together almost a quarter of all users in the country. At the time, it was the largest Facebook page in Zambia. Secondly, despite the relatively low number of users in the country, the page was extremely active for a short period during the elections, with numerous posts initiated both by page administrators as well as by regular followers of the page. Posts often provoked hundreds of comments.

Thirdly, while before the ballot, the 'Ask Muvi TV' page was dominated by discussions on candidates in the popular 'Ready for Marriage' reality television show, the elections began to dominate posts several weeks before voting day. Although the page was primarily set up to enable the station to engage with its audiences, this pre-existing network of viewers could easily be mobilized in the context of the elections for other purposes not strictly related to the station or its programs. Most crucially, with delays in the announcements of the election results, both page administrators and users began to share provisional election results which normally only the Electoral Council of Zambia is authorized to announce on the state-controlled ZNBC. This turned the page into an important real-time source of election news, bringing together information from different sources not available on mainstream media. 
Figure 1: Screenshot of ‘Ask Muvi TV’ Facebook page

\begin{tabular}{|c|c|}
\hline \multirow{6}{*}{ 量目 } & \multirow{2}{*}{$\begin{array}{l}\text { Ask Muvi TV } \\
\text { Counted and verified } 85 \text { constituencies. so far the results are follows: } \\
\text { presidential polls results - Sata } 639,787 \text { ( } 42.9 \%) \text { - RB } 542,362(36.41 \%), \mathrm{HH}- \\
247,284(16.6 \%) \text {, Chipimo } 5,764(0.39 \%) \text {, milupi } 5,7640.39 \%, \text { Kaunda } 5,644 \\
(0.38 \%) \text {, nawakwi } 3,602(0.24 \%) \text {, magande } 3,593(0.23 \%) \text {, miyanda } 2,331 \\
(0.16 \%) \text { Mutesa } 1,269(0.09 \%)\end{array}$} \\
\hline & \\
\hline & \multirow[t]{2}{*}{ Like $\cdot$ Comment $\cdot$ Share $\cdot 22$ September at 13:01 } \\
\hline & \\
\hline & View all 146 comments \\
\hline & Write a comment... \\
\hline & Ask Muvi TV \\
\hline $\mathbf{\Omega}$ & $\begin{array}{l}\text { Latest presidential polls results - Sata } 639,787(42.9 \%) \text { - RB } 542,362 \\
(36.41 \%) \text {, } \mathrm{HH}-247,284(16.6 \%) \text {, Chipimo } 5,764(0.39 \%) \text {, milupi } 5,764 \\
0.39 \% \text {,Kaunda 5,644 }(0.38 \%) \text {, nawakwi } 3,602(0.24 \%) \text {,magande } 3,593 \\
(0.23 \%) \text {, miyanda } 2,331(0.16 \%) \text { Mutesa } 1,269(0.09 \%)\end{array}$ \\
\hline & Like ' Comment ' Share ' 22 September at 12:56 ' \\
\hline & 68 people like this. \\
\hline & View all 116 comments \\
\hline & Write a comment... \\
\hline
\end{tabular}

\section{Methodology}

The analysis part of this study examined posts on the 'Ask Muvi TV' Facebook page between 10 September and 13 October 2011 (the elections took place on 20 September 2011). For technical reasons, it only comprised posts made by the page administrators and other Facebook users and did not include comments on these posts. In order to compile the dataset, all posts on the Facebook page were converted into a PDF document which was 449 pages long. A key advantage was that this provided a good sense of the original Facebook layout that users were exposed to. All posts were coded according to the nature and purpose of user engagement and three major themes were identified: 1) posts which addressed the Muvi TV station by commenting on their programs, making requests for specific programs, praising the station for its election coverage (often accompanied by critiques of other stations such as the state broadcaster) and asking the page for news updates on the elections; 2) posts which shared provisional election results, information from other media sources, witness accounts of outbreaks of violence in specific locations and reports on election irregularities; and 3) posts which campaigned for particular candidates in the elections or celebrated their victory. Apart from analyzing the discursive aspects of posts, the 'meta-features' of posts were also examined such as the time at 
which they were posted. To gain insights into the purpose and management of the 'Ask Muvi TV' Facebook page, an interview with a Muvi TV representative was conducted.

In addition to the analysis of Facebook posts, twenty-five semi-structured interviews were carried out in 2011 with a range of residents from different class backgrounds based in Lusaka, Zambia's capital city. The main purpose of the interviews was to gain a better understanding of mobile phone user practices in general and how users perceived the role of mobile phones during elections. Interview questions focused on the purposes of individual mobile phone use; the positive and negative features of mobile phones; and the role of mobile phones and other media forms (radio, television, press) in the elections (to receive information, to share information and to debate issues). Fieldwork took place in two different locations which represent two sides of the bifurcated, postcolonial city (Myers 2006): the upmarket Arcades Shopping Mall which is located in a low-density suburb of Lusaka and the informal, low-income Soweto Market situated close to the city center. Interviewees were randomly selected and most interviews were conducted in English and some in local Zambian languages such as Chibemba and Chinyanja. All interviews were transcribed, translated and coded thematically.

As stated before, the number of Facebook users in Zambia at the time was minimal and mainly represented 'early adopters'. While no formal statistics on Facebook users in urban and rural areas in Zambia were available, it is highly likely that most Facebook users were based in urban centers and were relatively well-off, with few users in rural areas having access (see also Wyche and Baumer 2017). Most interviewees who used mobile social media were those frequenting the up-market Arcades Shopping Mall rather than the low-income Soweto Market. The aim of this article is not to get a representative picture of mobile social media use in Zambia but to understand and explain the lively exchange of messages on the 'Ask Muvi TV' Facebook page during the election period. Apart from interviews, I participated as much as possible in 'the everyday life of elections' by getting a sense of the election mood in public transport, watching election results in public spaces, and attending a number of party rallies.

While Facebook posts classified under themes 2 and 3 demonstrated how the page transformed itself into a space for sharing information in the run-up to the elections, posts categorized under theme 1 commented on the users' experiences of Muvi TV, social media and other media forms such as radio during the elections. These comments were particularly revealing in understanding the relational affordances of mobile social media publics and spoke well to the interview data. Although not all mobile social media users directly engaged with the 'Ask Muvi TV' Facebook page, it was useful to learn more about their general mobile phone use and the role they imagined these to play in the elections. The interview and participant observation data enabled me to make better sense of the Facebook page posts and to understand their role within Zambia's wider communicative landscape during the elections.

\section{Identifying relational affordances of mobile social media}

How can we explain the transformation of the 'Ask Muvi TV' Facebook page into a mobile social media public during the September 2011 elections? What afforded the fast-paced discussions on the page which often provoked hundreds of comments to the page's status updates? This section identifies three key relational affordances of mobile social media publics: infrastructure, home-based access and temporality, which emerged out of the interaction between technology and platforms, users and their physical, mediated and political environment. 


\section{Infrastructure}

Existing analyses of mobile phone and social media affordances often focus on the intrinsic features of technological objects and fail to examine how these objects depend on, and relate to, other forms of infrastructure to afford their uses. This section identifies three forms of infrastructure as relational affordances which help to explain the lively exchanges on the 'Ask Muvi TV' Facebook page: the digital infrastructure of social media platforms, Facebook's integration with mobile network infrastructure, and the physical infrastructure that powers smartphones.

\section{Digital platform infrastructure}

In order to explain the lively exchanges on the 'Ask Muvi TV' Facebook page, it is crucial to take into account the digital platform infrastructure (Plantin et al., p. 2016) provided by social media corporations which organizes online communication in a particular way, choreographs collective action, shapes sociality and engineers publics (Gerbaudo, 2012; Van Dijck, 2013; Tufekci, 2014). The nature of individual timelines is shaped by algorithms which enable Facebook to determine what information users see and what remains hidden. Apart from algorithmic control, scholars have also emphasized the role of page administrators who are often deemed to be crucial in influencing the way in which users engage and participate in discussions on Facebook pages (Gerbaudo, 2012; Poell and van Dijck, 2016). As Poell and van Dijck (2016, p. 23) have argued, '[page administrators] control who can add posts to a page or start a photo gallery or event, and they can ban unruly users. Users, in turn, are often restricted to liking, sharing, and commenting on admin posts'. However, digital platform infrastructure is malleable and is not always used as intended.

A key factor that explained the lively exchanges on the 'Ask Muvi TV' Facebook page was precisely the absence of editorial control by page administrators, which related to the broader media landscape within which the Facebook page was situated. While Poell and van Dijck (2016) and others emphasize the power of page administrators, the 'Ask Muvi TV' page was subject to much less control from human mediators. Users had more power than just liking, sharing or commenting. They were able to initiate their own posts. For example, just as the state broadcaster ZNBC had announced the results of nearly all constituencies in the early hours of 23 September 2011, they opted to show an outdated film instead of continuing their coverage on the elections. This provoked a number of angry comments from users on the 'Ask Muvi TV' Facebook page who were kept in agony anxiously waiting for the final vote count.

In an interview with a station representative, Muvi TV justified the lack of intervention by the page administrators by arguing that too much content on the public broadcaster ZNBC was already subject to state control. Hence, the importance of providing a 'free space' for Zambians to express themselves.4 Because of the lack of interference with content, the page not only became a vertical information hub between the television station and audiences but also a horizontal or lateral space for users to share information. This suggests that users have some agency in shaping platform infrastructure to suit their own ends. It also demonstrates that the affordances of mobile social media should be understood in relation to the wider mediated context of which they are a part. 
Figure 2: Screenshot of 'Ask Muvi TV' Facebook page

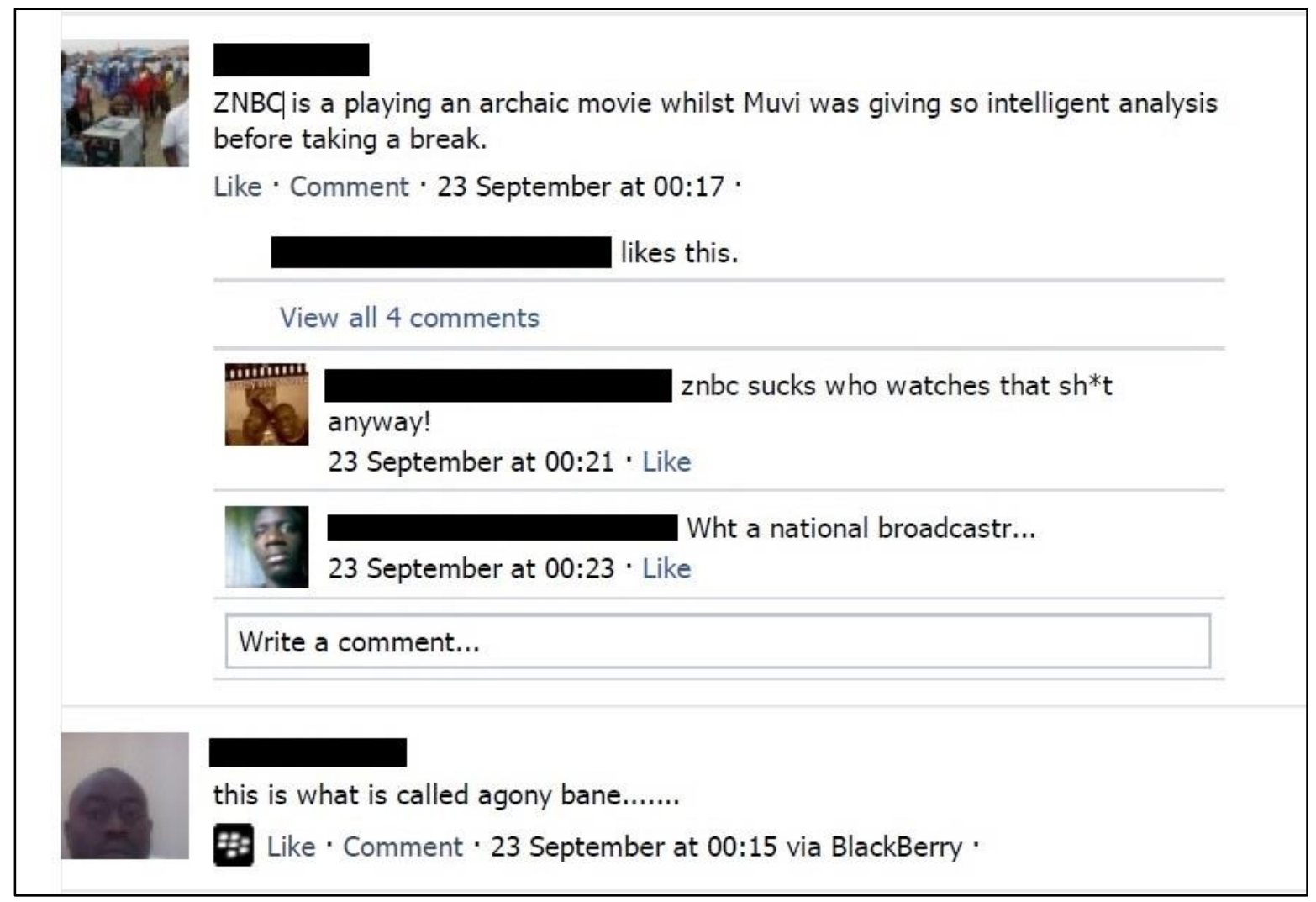

\section{Mobile network infrastructure}

To access Facebook's digital platform infrastructure, 'Ask Muvi TV' users mostly relied on mobile network infrastructure. Internet users in the Global North may use broadband internet on a desktop or PC as well as mobile phones to access social media but Global South internet users tend to rely on mobile-only or mobile-centric internet access. Furthermore, their mobile internet use is often profoundly shaped by social media platforms because of subsidized access to apps such as Facebook, Twitter and WhatsApp (Willems, 2016a). Zero-rated apps such as Facebook Free Basics or social media data bundles - which provide unlimited access to different social media platforms over a certain period, e.g. an hour, day, week, month - ensure relatively cheap access to social media as compared to accessing other parts of the internet which are not subsidized. While a majority of Global North dwellers use relatively affordable mobile data subscription packages which ensure continued access to all parts of the internet (as long as data have not been used up), the bulk of Global South users depend on more intermittent prepaid phone and data arrangements which often restrict access to social media.

Hence, while smartphones have widened access to the internet in the Global South, the quality of access remains compromised. Zambians relied on mobile internet to participate in the 'Ask Muvi TV' Facebook group for several reasons. While internet cafes were still popular in 2011, these operated with limited opening hours. Many posts and comments on the 'Ask Muvi TV' Facebook group were posted in the evenings when internet cafes were closed. Fixed broadband internet access was only available to a small minority of users, with only 15,902 connections in 2011 (equal to only 0.12 percent of the population) while nearly 380,000 people 
were using mobile broadband (equal to 2.8 percent of the population) (ITU, 2018).5 Mobile internet allowed any time access to the 'Ask Muvi TV' Facebook group without the need for physical travel to a public access point, provided of course that users had an active data package on their phone to access social media.

\section{Physical infrastructure}

Apart from digital platform and mobile network infrastructure, mobile social media also rely on physical infrastructure to function. In his ecological approach to affordances, Gibson (1979) situated technological objects within an environment that afforded certain uses. Similarly, it is crucial to take into account the wider contexts that enable mobile social media to operate. Apart from the smartphone itself, electricity or sufficient battery power are essential to keep mobile social media running. While this may be taken for granted in the Global North, a stable electricity supply is not always available in Global South countries. For example, in Zambia, electricity provision is erratic and frequent power cuts are common. However, despite these requirements, smartphones still have a comparative advantage over other types of media such as television and radio sets which require a constant electricity supply (unless these are battery operated). If adequately charged, smartphones can enable people to access information during power cuts.

While television is often singled out as a crucial medium during elections in AngloAmerican contexts (particularly, prior to the popularity of social media), access to television continues to be somewhat of a luxury in many Global South contexts due to the high costs of television sets or satellite decoders or poor coverage in certain areas. For example, in Zambia, only 35.5 per cent of the population has access to a television set. 6 The comparative advantage of mobile social media over television sets was illustrated by several comments on the 'Ask Muvi TV' page from Facebook users who were unable to watch Muvi TV because they did not have the required satellite decoder, resided in an area where there was no TV signal, or could not watch television because there was a power cut in their area:

[Muvi TV], [w]ill you update us via Facebook because we are in places where we can't access TV?7

Any updates on the cabinet? Please, Muvi, update us. Some of us are far from where we can get a TV signal.8

Muvi TV, kindly delay the airing of the PF documentary because most Lusaka areas don't have power.9

While these Facebook users did not have direct access to the station, they were able to access the latest news via the station's Facebook page. Because of low landline density (and therefore few fixed broadband internet connections) and low ownership of computers and laptops, smartphones were the key devices through which Zambians were able to participate in the 'Ask Muvi TV' Facebook page at any time (assuming access to a mobile data package and a charged battery).

In summary, the 'Ask Muvi TV' page therefore enjoyed several comparative advantages that afforded its use over other forms of media and communication technology. First of all, the page was subject to less control as compared to Zambia's wider media landscape, enabling sharing of information and a relatively 'free' debate on the elections. Secondly, accessing the page was more affordable to mobile internet users than accessing other parts of the internet due 
to subsidized data bundles. Finally, in contrast with other forms of media, smartphones were more reliable during periods of electricity shortage.

\section{Home-based access}

When discussing the political implications of digital media, scholars have often emphasized portability in public space as a key affordance of mobile phones which allow protesters to coordinate and communicate while demonstrating. As Donner $(2015, \mathrm{p}$. 98) has argued, '[b]y combining on-the-go access to networks that switch and serve, the smartphone is a protest tool par excellence'. Early work on digital media and politics credited mobile phones with enabling popular uprisings against Philippine President Joseph Estrada in January 2001 (Rafael, 2003). However, in Zambia, the opportunity to use mobile social media at home — in a private rather than public space - was potentially more significant and transformative than the ability to use smartphones on the streets. Because of low landline density, mobile phones were for many Zambians the first devices that linked their homes to telephone services (initially) and internet connectivity (subsequently). Prior to the mobile internet, most Zambians relied on internet cafes, workplaces or libraries to access the internet. The capacity of the smartphone to connect users with unknown others, also referred to as 'informational mobility' (Sheller and Urry, 2003, p. 108), from the privacy of one's home, is particularly crucial in situations in which critical information is not available via other means or where physical mobility is challenged due to security concerns as was the case during the 2011 Zambian elections.

While in the run-up to the elections, people travelled and chatted about the elections in public transport, markets and on the streets, most Zambians decided not to travel immediately after Election Day but instead opted to stay home out of fear of being caught up in election violence. The tense political situation in Lusaka was largely due to the delays in the announcement of election results by the Electoral Commission of Zambia (ECZ) on ZNBC which caused widespread anxiety. The anxiety was reinforced by a strong local discourse on the importance of peace and stability. In the light of these security concerns, Zambians' physical mobility in Lusaka was restricted which made it harder to access internet cafes which were mostly located in shopping malls or in the city center (Cairo Road area). Furthermore, these establishments also had limited opening hours which meant that internet access was not available during late evenings and throughout the night.

Despite these limitations, traffic on the 'Ask Muvi TV' was intense both during the day and throughout the night. For example, a post made on the page after midnight, announcing Michael Sata as Zambia's new president provoked 296 comments. 
Figure 3: Screenshot of ‘Ask Muvi TV’ Facebook page

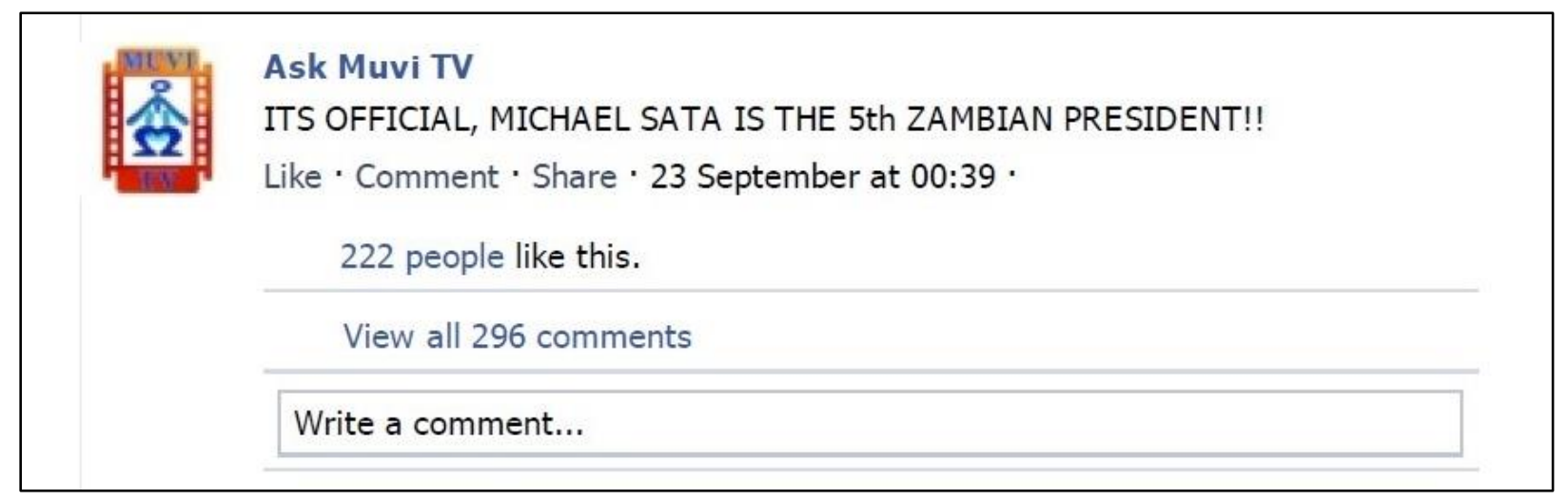

This can be explained by the growing availability of the mobile internet during the period of research, as a college student confirmed as follows:

\footnotetext{
Researcher: But do you think they [other students using the Ask Muvi TV Facebook page] mostly access it from campus or from their phone?

Interviewee: From their phone, most of them, it is their phone. Only few, I think few, only few manage to have laptops and what I saw, yes, mostly it is through their phone. Because even at night, maybe like at midnight, you see many people still using their mobile phones. 10
}

Prior to the mobile internet, home-based access to the internet was rare in Zambia due to the small number of fixed phone lines and the high costs of fixed broadband internet packages offered by internet service providers. Mobile social media enabled a small minority of Zambians to access information on the elections from the comforts and safety of their private homes. The shift to mobile internet access had important political implications as it enabled the sharing of information in situations where public gatherings are not feasible or travelling is perceived as risky or dangerous. So far, the bulk of literature on mobile phones and politics has emphasized their use in public space, as the quintessential tool of on-the-go protests and political mobilization. Instead, this section has revealed the political significance of mobile social media access in private spaces. In highlighting the way in which mobile social media use is shaped by spatial contexts, it has identified home-based access as a key relational affordance of mobile social media publics.

\section{Temporality}

Apart from the spatial affordances of mobile social media publics, temporality featured as another important relational affordance that helps to explain the emergence of the lively exchange of messages around the elections on the 'Ask Muvi TV' Facebook page. Naturally, an important feature of the 'Ask Muvi TV' page was its real-time nature, a key affordance of mobile social media also frequently cited in the wider literature on social media. As reflected by its name, the 'Ask Muvi TV' Facebook page encouraged audiences and users to engage with the station and to ask questions. Many comments on the page were indeed addressed directly at the station but closer to voting day, posts increasingly began to revolve around the elections.

The real-time nature of comments on the 'Ask Muvi TV' Facebook page was extremely important in the Zambian context, given the very limited live election coverage on radio and television. Although some radio stations broadcast throughout the night, there was no 24-hour 
television news channel that provides running coverage. Hence, social media became an important space where information could be sourced, shared or provided in real-time. As a university graduate told me: 'on Facebook there are some guys who are linked and they pass news to some news sites, some local news. So they will post a lot of latest things. Before you even hear it on the radio or read it in the newspaper, we discuss it. By the time they put it, it is history already. So that is one of the reasons why I am always on Facebook'.11 The 2011 elections were highly contested and voters anxiously awaited news on the results. With delays in announcements of the official results and an injunction imposed on Muvi TV (and a number of private radio stations) after they were accused of illegally sharing election results (the Electoral Council of Zambia is normally only authorized to do this on the state broadcaster ZNBC), the page became an important resource for the latest updates on the elections.

However, apart from enabling users to engage with others in real-time, what was also crucial was visitors' ability to access the 'Ask Muvi TV' page archive at any time. As already mentioned in the previous section, in the absence of mobile internet, a majority of Zambians would need to physically travel to an internet café or other access point to access the web and would be restricted to the opening times during office hours. However, smartphones enabled internet access at any time of the day, provided of course that a mobile data package was available. This enabled users not only to engage with content in real-time but also allowed page users to practice what could be described as 'targeted page browsing', i.e. explicitly visiting the 'Ask Muvi TV' Facebook page to catch up on the latest news updates from the station or posts made by other visitors. This offered them access to a large number of archived updates and comments, beyond real-time engagement on their individual timeline. As indicated above, not all Zambians had good access to Muvi TV from their homes but still wanted to keep up-to-date with the station's coverage during the election period. Accessing the archive of posts on the station's Facebook page enabled them to catch up on the latest news at any time and not just in real-time. A number of posts explicitly requested news updates from the 'Ask Muvi TV' page: 'Muvi, please find out for us and update us why ECZ [Electoral Commission of Zambia] is taking long to announce the results. We are all clouded by rumours. We don't want to be cheated. Get us official info. Thanking you in advance'.12

Any time access was also significant given the fragmented nature of mobile internet access in Zambia. Internet access in Global North contexts is often continuous via monthly subscription-based mobile data or fixed broadband packages. This produces a user experience which Turkle (2011: 227) has described as follows in relation to the US context: '[a]lways on and (now) always with us, we tend the Net, and the Net teaches us to need it'. However, Zambian smartphone users tend to rely on daily or weekly 'social data bundles' which provide unlimited access to social media during a particular time period. Therefore, mobile connectivity is not constant or 'always on' but can be interrupted when data bundles cannot be purchased for financial or logistical reasons. Real-time engagement may thus not always be feasible, making any time access to archived social media content very significant. This again demonstrates that the affordances of mobile social media publics are relational. On the one hand, the real-time nature of mobile social media contrasts with the relative lack of live election coverage on television and radio, giving Facebook a comparative advantage over traditional broadcast media. On the other hand, the fragmented nature of mobile internet access should be taken into account in order to make sense of user engagement with the 'Ask Muvi TV' Facebook page. 


\section{Conclusion}

As Grosfoguel (2007: 213) has argued, 'Western philosophy and sciences are able to produce a myth about a Truthful universal knowledge that covers up, that is, conceals who is speaking as well as the geo-political and body-political epistemic location in the structures of colonial power/knowledge from which the subject speaks'. It is important to challenge this 'knowledge from nowhere' and to provincialize existing analyses of the affordances of digital technology which present themselves as universal but often strictly draw on Global North contexts without explicitly stating as such. African users of digital technology are rarely presented as active producers of digital culture. Black users more generally are often seen as 'poster children for the disabling digital divide discourse' (Everett 2009: 62), while Global South users are frequently framed as using digital media for purely instrumental or utilitarian purposes such as healthcare, education or employment (Arora 2019). Instead of reproducing these discourses, this article has examined Zambian digital media users as 'early adopters' of mobile social media who inventively appropriated the 'Ask Muvi TV' Facebook page to share information on the September 2011 elections.

The analysis of Zambians' initial uptake of technology demonstrated the comparative advantages of mobile social media in constituting publics over other forms of media during intensely political periods such as elections. This challenges and problematizes previous analyses of mobile social media publics - often based on Global North contexts - which have emphasized negative (constraining) affordances like the control exerted by Facebook page administrators and positive (enabling) affordances such as the 'always-on' nature of mobile social media use and their 'on-the-go' access in public spaces. Similar to other Global South contexts, mobile social media in Zambia were subject to less control than broadcasting media and provided real-time, 24/7 content. They were cheaper to access than other parts of the internet. They were more reliable during power cuts than other media such as television and radio. They could be accessed in private spaces at any time as compared to public internet access points which required physical travel and only operated during limited opening hours. Infrastructure, home-based access and temporality emerged as key relational affordances of mobile social media publics.

The notion of relational affordance does not only account for different uses of technology across geographical regions but also bears in mind change over time. The relational affordances of mobile social media publics may shift as contexts evolve. While only 2.8 per cent of Zambians were able to access the mobile internet in 2011, this increased to 32.3 per cent during the country's next elections in 2016.13 By then, the number of Facebook users had also increased tenfold to 1.4 million.14 As a result of this expanded digital access, mobile social media featured more strongly in the 11 August 2016 elections. Political parties drew more heavily upon social media in their campaigns, actively curated Facebook pages with regular status updates, videos and images of party rallies, and live-streamed press conferences (Willems, 2016b). While the lively exchanges about the elections on the 'Ask Muvi TV' Facebook page in 2011 were possible due to limited interference from the page administrators, many Zambian Facebook pages began to curate content more carefully in 2016, not allowing users to initiate any posts but instead only enabling them to comment on official posts. This reflects the more instrumental uses of social media which became more widespread in 2016 and saw 'ad hoc publics' slowly being transformed into 'calculated publics' (Bruns and Burgess 2015).

The concept of relational affordance examines technological affordances as a product of the interaction between technology, user and context. Instead of treating mobile devices and 
social media platforms as separate (physical or digital) objects which function independently from the environments in which they are located, this article has demonstrated how physical, mediated and political contexts shape the way in which mobile social media are used.

Technological affordances are far from universal but take on different shapes across the globe. Hence, the internet is not a singular space but a collection of multiple global internets which adopt and fulfill different roles in different settings over time.

\section{References}

Arora, P. (2019). The next billion users: digital life beyond the West. Cambridge, MA: Harvard University Press.

Baym, N., \& boyd, d. (2012). Socially mediated publicness: an introduction. Journal of Broadcasting \& Electronic Media, 56(3), 320-329.

Boyd, d. (2010). Social network sites as networked publics: affordances, dynamics and implications. In Z. Papacharissi (Ed.), A networked self: identity, community and culture on social network sites (pp. 39-58). New York: Routledge.

Bruns, A., \& Burgess, J. (2015). Twitter hashtags from ad hoc to calculated publics. In N. Rambukkana (Ed.), \#Hashtag publics: the power and politics of discursive networks (pp. 13-28). New York, NY: Peter Lang.

Bucher, T., \& Helmond, A. (2017). The affordances of social media platforms. In J. Burgess, T. Poell and A. Marwick (Eds.), SAGE handbook of social media. London, Sage.

Burrell, J. (2012). Invisible users: youth in the internet cafés of urban Ghana. Boston, MA: MIT Press.

Chan, A. S. (2014). Networking peripheries: technological futures and the myth of digital universalism. Cambridge, MA: MIT Press.

Christensen, C. (2011). Discourses of technology and liberation: state aid to net activists in an era of 'Twitter Revolutions'. The Communication Review, 14(3), 233-253.

Dijck, J. van (2013). The culture of connectivity: a critical history of social media. Oxford: Oxford University Press.

Dijck, J. van, \& Poell, T. (2015) Social media and the transformation of public space. Social Media + Society, 1(2), 1-5.

Donner, J. (2015). After access: inclusion, development, and a more mobile internet. Cambridge, MA: The MIT Press.

Dwyer, M., \& Molony, T. (2019). Social media and politics in Africa: democracy, censorship and security. London: Zed Books.

Ellison, N. B., \& Vitak, J. (2015). Social network site affordances and their relationship to social capital processes. In S. S. Sundar (Ed.), The handbook of the psychology of communication technology (pp. 203-227). Oxford: Wiley-Blackwell.

Enli, G., \& Moe, H. (2015). Social media and election campaigns: key tendencies and ways forward. London, UK: Routledge.

Everett, A. (2009). Digital diaspora: a race for cyberspace. New York, NY: State University of New York Press.

Gerbaudo, P. (2012). Tweets and the streets: social media and contemporary activism. London, UK: Pluto Press.

Gibson, J. J. (1986) [1979]. The ecological approach to visual perception. Hillsdale, NJ: Lawrence Erlbaum Associates. 
Goggin, G. (2014). Facebook's mobile career. New Media \& Society, 16(7), 1068-1086.

Grosfoguel, R. (2007). The epistemic decolonial turn. Cultural Studies, 21(2-3), 211-23.

Highfield, T. (2016). Social media and everyday politics. Cambridge: Polity.

Hyde-Clarke, N. (2006). The urban digital divide: a comparative analysis of internet cafés in Johannesburg. Review of African Political Economy, 33(107), 150-156.

Ilten, C. (2015). "Use your skills to solve this challenge!": the platform affordances and politics of digital microvolunteering, Social Media + Society, 1(2), 1-11.

International Telecommunication Union (ITU) (2018). Key ICT indicators for developed and developing countries and the world (totals and penetration rates) (2005-2018). Retrieved from https://www.itu.int/en/ITU-D/Statistics/Documents/statistics/2018/ITU_Key_20052018_ICT_data_with\%20LDCs_rev27Nov2018.xls

Khazraee, E., \& Novak, A. N. (2018). Digitally mediated protest: social media affordances for collective identity construction. Social Media + Society, 4(1), 1-14.

Knappett, C. (2005). Thinking through material culture: an interdisciplinary perspective. Philadelphia, PA: University of Pennsylvania Press.

Mascheroni, G., \& Vincent, J. (2016). Perpetual contact as a communicative affordance: Opportunities, constraints, and emotions. Mobile Media \& Communication, 4(3), 310326.

Miller, D., \& Sinanan, J. (2017). Visualising Facebook. London: UCL Press.

Mwesige, P. G. (2004). Cyber elites: a survey of internet café users in Uganda. Telematics \& Informatics, 21(1), 83-101.

Myers, G. A. (2006). The unauthorized city: Late colonial Lusaka and postcolonial geography. Singapore Journal of Tropical Geography, 27(3), 289-308.

Nagy, P., \& Neff, G (2015). Imagined affordance: reconstructing a keyword for communication theory. Social Media + Society, 1(2), 1-9.

Norman, D. A. (1988). The psychology of everyday things. New York, NY: Basic Books.

Papacharissi, Z. (2015). Affective publics: sentiment, technology, and politics. Oxford: Oxford

Plantin, J.-C., Lagoze, C., Edwards, P. N., \& Sandvig, C. (2018). Infrastructure studies meet platform studies in the age of Google and Facebook. New Media \& Society, 20(1), 293310.

Poell, T., \& Dijck, van J. (2016). Constructing public space: global perspectives on social media and popular contestation. International Journal of Communication, 10, 226-234.

Rafael, V. L. (2003). The cell phone and the crowd: messianic politics in the contemporary Philippines. Public Culture, 15(3), 399-425.

Rambukkana, N. (2015). Hashtag publics: the power and politics of discursive networks. New York, NY: Peter Lang.

Schrock, A. R. (2015). Communicative affordances of mobile media: portability, availability, locatability, and multimediality. International Journal of Communication, 9(1), 12291246.

Sheller, M., \& Urry, J. (2003). Mobile transformations of 'public' and 'private' life. Theory, Culture \& Society, 20(3), 107-125.

Tufekci, Z. (2014). Engineering the public: Big data, surveillance and computational politics. First Monday, 19(7).

Turkle, S. (2011). Alone together: why we expect more from technology and less from each other. New York, NY: Basic Books.

Varnelis, K. (2008). Networked publics. Cambridge, MA: MIT Press. 
Wasserman, H., \& Mbatha, L. (2017). Popular engagement with tabloid TV: a Zambian case study (pp. 71-92). In W. Willems and W. Mano (Eds.), Everyday media culture in Africa: audiences and users (pp. 71-92). London, UK: Routledge.

Willems, W. (2016a). Beyond Free Basics: Facebook data bundles and Zambia's social media internet, Africa at LSE blog, https://blogs.lse.ac.uk/africaatlse/2016/09/01/beyond-freebasics-facebook-data-bundles-and-zambias-social-media-internet/

Willems, W. (2016b). Facebook live-streaming, drones and swag selfies: youth culture and visual social media in \#ZambiaDecides, Africa at LSE blog, https://blogs.lse.ac.uk/africaatlse/2016/08/31/facebook-live-streaming-drones-and-swagselfies-youth-culture-and-visual-social-media-in-zambiadecides/

Wyche, S., \& Baumer, E. P. S. (2017). Imagined Facebook: an exploratory study of non-users' perceptions of social media in rural Zambia. New Media and Society, 19(7), 1092-1109.

Zayani, M. (2015). Networked publics and digital contention: the politics of everyday life in Tunisia. Oxford: Oxford University Press.

1 It should be noted that user statistics - such as those included in the International Telecommunication Union's (ITU) ICT database - offer estimates which are often derived from data provided by mobile phone operators. These estimates may deviate from actual usage patterns. For example, official data underestimate the common practice of mobile phone sharing which has been particularly prevalent in different parts of the Global South as well as users switching between multiple SIM cards from different mobile network providers which prevailed in my Zambia study.

${ }^{2}$ In the meantime, the original page (https://www.facebook.com/askmuvi) is no longer available and has been replaced with a new page (https://www.facebook.com/muvitvsocial).

3 Source: Internet World Stats Usage and Population Statistics, retrieved from http://www.internetworldstats.com/africa.htm\#zm

4 Interview with Muvi TV representative, Lusaka, 26 September 2011.

5 See ICT indicators, Zambia Information and Communications Technology Authority (ZICTA), retrieved from http://onlinesystems.zicta.zm:8585/statsfinal/ICT\%20Indicators.html

6 See: Zambia Information and Communication Technology Authority (ZICTA) (2014). 2013 ICT Country Survey Report - Zambia. Lusaka: ZICTA, p. 18, available from:

https://www.zicta.zm/Views/Publications/ICT\%20Survey\%202013\%20Report.pdf (last accessed: 5 October 2019). 7 Original, edited comment on Muvi TV Facebook page, poster anonymised, 20 September 2011, 05h22.

8 Original, edited comment on Muvi TV Facebook page, poster anonymised, 28 September 2011, 11h56.

9 Original, edited comment on Muvi TV Facebook page, poster anonymised, 15 September 2011, 19h23.

10 Interview with young female college student in Arcades Shopping Mall, 27 September 2011.

11 Interview with university graduate in Arcades Shopping Mall, 21 September 2011.

12 Original, edited comment on Muvi TV Facebook page, poster anonymised, 21 September 2011, $10 \mathrm{~h} 17$.

13 See ICT indicators, Zambia Information and Communications Technology Authority (ZICTA),

http://onlinesystems.zicta.zm:8585/statsfinal/ICT\%20Indicators.html

14 See Internet World Stats: https://www.internetworldstats.com/af/zm.htm 